\title{
POLÍTICA COMERCIAL, FLUJOS MERCANTILES Y NEGOCIOS: BUENOS AIRES Y MONTEVIDEO FRENTE AL COMERCIO EXTERIOR RIOPLATENSE EN EL SIGLO XIX*
}

POR

\author{
ROBERTO SCHMIT Y MIGUEL ROSAL
}

Instituto Ravignani-CONICET

Este trabajo tiene como objetivo analizar el ritmo de crecimiento de las exportaciones rioplatenses y la competencia mercantil de los puertos de Buenos Aires y Montevideo en pos de hegemonizar el flujo comercial. A partir del estudio cuantitativo y cualitativo del tráfico y las políticas comerciales implementadas entre 1830 y 1850, presentamos nuevas evidencias que replantean las ventajas y desventajas que tuvieron los negocios en el espacio rioplatense desde mediados del siglo XIX.

\section{INTRODUCCIÓN}

Las tierras de la cuenca del Río de la Plata, especialmente las que integran actualmente la zona sur del Brasil, la República Oriental del Uruguay y las regiones del litoral y de la pampa de la Argentina fueron desde fines del siglo XVIII y sobre todo durante el XIX los centros más dinámicos de la producción pecuaria y conformaron uno de los núcleos más significativos del comercio atlántico en Sudamérica ${ }^{1}$.

* Versiones anteriores de este trabajo fueron presentadas en las V Jornadas Interescuelas/Departamentos de Historia y I Jornadas Rioplatenses Universitarias de Historia, Montevideo, septiembre de 1995, y en el Programa de Historia Argentina del siglo XIX, Instituto de Historia Argentina y Americana «Dr. Emilio Ravignani», Facultad de Filosofia y Letras, UBA, Buenos Aires, agosto de 1996; agradecemos los comentarios recibidos en ambas ocasiones. También apreciamos los realizados por los árbitros anónimos de la Revsita de Indias.

1 Tulio HALPERIN DONGHI, Reforma y disolución de los imperios ibéricos 1750-1850, Madrid, Ed. Alianza, 1985, pp. 275-290. John LYNCH, «Las Repúblicas del Río de la Plata», en Historia de América Latina, vol. 6, Barcelona, Ed. Crítica, 1991, pp. 264-315. 
Dentro de este gran espacio económico los ríos Paraná y Uruguay fueron las mejores vías para integrar un vasto territorio al mercado ultramarino ya que por ellos circulaban los bienes de exportación e importación, los cuales podían salir o entrar únicamente por los puertos de Buenos Aires y Montevideo².

\section{PRINCIPALES PUERTOS DE LA CUENCA \\ DEL RIO DE LA PLATA}

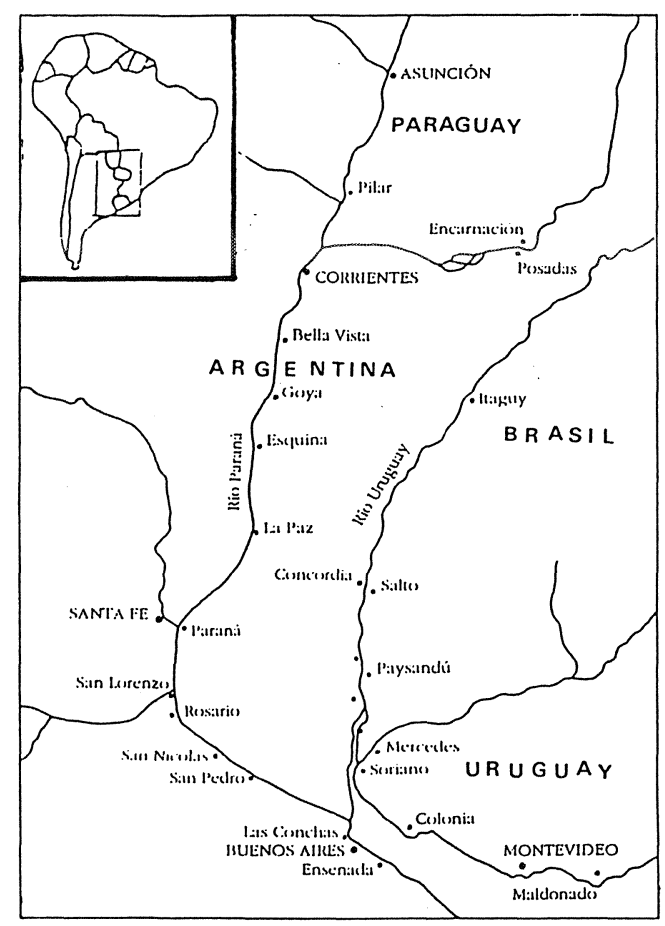

2 Roberto SCHMIT, «Comercio y mercado en el Litoral argentino durante la primera mitad del siglo XIX», en Jorge SILVA RIQUER, Juan Carlos Grosso y Carmen YUSTE (comp.), Circuitos mercantiles y mercados en Latinoamérica, siglos XVIII y XIX, Instituto Mora y UNAM, México, 1995, pp. 291-325. SCHMIT y Miguel A. RosAL, «Las exportaciones del Litoral argentino al puerto de Buenos Aires entre 1783 y 1850», en Revista de Historia Económica, año XIII, n 3, Madrid, Alianza Editorial, otoño 1995, pp. 581-607. Thomas WhighaM, «The Back-Door Approach: The Alto Uruguay and Paraguayan Trade, 18101852», Revista de Historia de América, n 109, México, I.P.G.H., 1990, pp. 45-67. Lilia Inés ZANOTTI de MEDRANO, «Un ciclo comercial en la Cuenca del Plata (1852-1920)», Revista Complutense de Historia de América, n 18, Madrid, 1992, pp. 219-239. 
El diseño de esa red de circuitos mercantiles potenció durante la primera mitad del siglo XIX dos conflictos básicos: uno, entre algunas regiones interiores y los porteños en torno a la libre navegación de los ríos ${ }^{3}$; y otro, entre Buenos Aires y Montevideo por lograr la hegemonía en el manejo del tráfico.

En cuanto a esta última pugna, la competencia se remontaba a la época colonial, en especial a partir de la creación de la aduana de Montevideo en 1778. Pero la situación se agravó con el reconocimiento de la independencia de la República Oriental del Uruguay en 1828. Desde entonces ambas plazas pusieron en práctica numerosas medidas tendentes a hegemonizar el comercio rioplatense, en el marco de una serie de conflictos políticos y militares, que se extendieron hasta la finalización de la Guerra Grande en el Uruguay y la caída en 1852 del régimen rosista en Buenos Aires ${ }^{4}$.

Numerosas investigaciones han puesto de relieve la importancia que tuvo la competencia entre puertos, y en la mayoría de ellas se plantea que el de Montevideo tenía mejores condiciones geográficas naturales que el de Buenos Aires; por ello insinuan que aquel puerto debió ser una peligrosa alternativa de competencia para los bonaerenses. Incluso algunos trabajos se preguntan si un hipotético fortalecimiento de los vínculos mercantiles del Litoral de los ríos con Montevideo no podría haber sido una opción para configurar un espacio económico-político contrario a los intereses de los porteños. Pero hasta el presente no existen trabajos comparativos y series comerciales que permitan testear esas hipótesis y esclarecer el desempeño que tuvieron los puertos de la cuenca del Plata ${ }^{5}$.

\footnotetext{
3 En nuestro trabajo, el término porteño se refiere exclusivamente al puerto de Buenos Aires. Llamamos provincias del interior rioplatense a Jujuy, Salta, Túcuman, Santiago del Estero, Córdoba, La Rioja, Catamarca, San Luis, San Juan y Mendoza. Por su parte, Santa Fe, Corrientes y Entre Ríos conforman el Litoral argentino.

4 Horacio PEREYRA, «Notas sobre la economía del Litoral argentino, 1820-1836», en Humanidades, t. 35, La Plata, Facultad de Humanidades y Ciencias de la Educación, Universidad Nacional de La Plata, 1960, pp. 123-159. Oscar ABADIE-AICARDI, «La política de tránsito y la rivalidad comercial entre Montevideo y Buenos Aires (1829)», en VI Congreso Internacional de Historia de América, t. 5, Buenos Aires, Academia Nacional de la Historia, 1982, pp. 387-413. Fernando JUMAR, «El Río de la Plata y sus relaciones atlánticas durante el siglo XVIII. Los rioplatenses y el Río de la Plata. Las modalidades del comercio rioplatense y los grupos locales, 1680-1777», en XIV Jornadas de Historia Económica, Córdoba, 1994.

5 Miron BuRgin, Aspectos económicos del federalismo Argentino, Buenos Aires, Ed. Solar/Hachette, 1960. HALPERIN DONGHI, «La expansión ganadera en la campaña de Bue-
} 
En función de aportar nuevas evidencias que permitan ilustrar el desempeño comercial del Río de la Plata, en este trabajo analizamos las siguientes cuestiones: ¿A qué ritmo crecieron las exportaciones rioplatenses? ¿Cómo circulaban en el espacio interior y hacia qué puerto iban? ¿Qué políticas arancelarias desplegaron los puertos ultramarinos? ¿Cómo se hacían los negocios en los mismos? Nuestra hipótesis es que desde 1830 en adelante los puertos de Buenos Aires y Montevideo iniciaron una fuerte puja por acrecentar su papel mercantil en la región; no obstante una serie de coyunturas muy cambiantes en los primeros años, finalmente el primero logró acentuar su hegemonía. Postulamos que esta situación se sostuvo en los estrechos vínculos comerciales que los porteños supieron conservar y acrecentar con el Litoral de los ríos y las ventajas que les significó poseer un hinterland apto para la expansión ganadera, junto al manejo de variados medios de pagos que dispuso este mercado. Todo ello le habría permitido a Buenos Aires estar convenientemente preparada para recibir en mayor medida que su oponente los frutos del proceso de modernización abierto hacia la segunda mitad del siglo XIX.

\section{LAS FRICCIONES EN EL COMERCIO DE LA CUENCA DEL RIO DE LA PLATA}

En la era poscolonial la navegación de la cuenca del Plata fue uno de los temas que generó permanentes conflictos y un gran debate entre los pueblos rioplatenses. A lo largo de cinco décadas se discutió acerca de la legitimidad de los derechos que tenía cada gobierno en imponer sus intereses locales sobre los de sus vecinos. En esas disputas también jugaron un rol importante las dos grandes po-

\footnotetext{
nos Aires (1810-1852)», Desarrollo Económico, n 1-2, Buenos Aires, 1963, pp. 57-110 y Revolución y Guerra. Formación de una elite dirigente en la Argentina criolla, Buenos Aires, Ed. Siglo XXI, 1972. José Carlos ChIARAMONTE, Mercaderes del Litoral. Economía y sociedad en la provincia de Corrientes, primera mitad del siglo XIX, México-Buenos Aires, Fondo de Cultura Económica, 1991. José Pedro BARRAN y B. NAHUM, Historia rural del Uruguay moderno, 8 vol., Montevideo, 1967-1978. BARRAN, Apogeo y crisis del Uruguay pastoril y caudillesco 1839-1875, Montevideo, Ed. Banda Oriental, 1988. Julio Millot y Magdalena BERTINO, Historia económica del Uruguay, 2 t., Montevideo, Fundación Cultura Universitaria, 1991 y 1996. Raúl JACOB, «Uruguay: Integración y desintegración de un pequeño mercado regional», Siglo XIX, n 14, México, 1993. pp. 211-238.
}

R. I., $1999, \mathrm{n}^{\circ} 215$ 
tencias marítimas de la época, Gran Bretaña y Francia, que procuraban obtener ventajas para sus actividades comerciales ${ }^{6}$.

Los nacientes estados poscoloniales tenían muchos motivos que los estimulaban a intentar establecer su predominio en el comercio del Plata. El control de esta región era vital, ya que allí convergía como en un plano inclinado una vasta red de circuitos mercantiles que por vías terrestres y fluviales abarcaba al Paraguay, el sur del Brasil, la costa de la Banda Oriental y las provincias de Corrientes, Entre Ríos, Santa Fe y Buenos Aires. ¿Qué plaza mercantil no quería manejar semejante cantidad de giros y fletes comerciales? Ante la escasez de recursos públicos, ¿qué Estado rehusaría la posibilidad de poder recaudar las rentas que este intenso tráfico generaba? ¿Cuál pueblo estaría dispuesto a pagar más caros los numerosos productos importados que consumía y a recibir peores precios por los que exportaba? ${ }^{7}$

Evidentemente, por todo lo señalado, durante la primera mitad del siglo XIX había mucho en discusión, pero en un contexto político-estatal en formación, donde imperaba una férrea defensa de los intereses locales, lograr un equilibrio, por medio de acuerdos equitativos, para evitar la hegemonía de algunas plazas comerciales fue desde un primer momento un serio problema que se debía resolver ${ }^{8}$.

6 La independencia del Estado Oriental en 1828, fruto de la política de Gran Bretaña -principal mediador de los acuerdos rioplatenses-, tenía como objetivo sostener un equilibrio en el Río de la Plata. Se pensaba que la presencia del nuevo Estado neutralizaría la posible hegemonía del Brasil o de la Argentina. Al respecto se puede consultar, entre otros, a Luis Alberto de Herrera, La misión Ponsomby, Buenos Aires, Eudeba, 1974 y Peter WINN, El imperio informal británico en el Uruguay en el siglo XIX, Montevideo, Ed. de la Banda Oriental, 1975.

7 Es importante no perder de vista el valor que tenía la recaudación aduanera para los intereses de los estados rioplatenses; tanto en Buenos Aires como en Montevideo representaba un promedio no inferior al $60 \%$ del total de la renta pública, lo cual la convertía en pieza clave para sostener el aparato estatal. Sobre el tema de las finanzas públicas se puede consultar, entre otros, a HALPERIN DONGHI, Guerra y finanzas en el Estado de Buenos Aires, Buenos Aires, Ed. Belgrano, 1982 y Eduardo ACEVEDo, Contribución al estudio de la historia económica y financiera de la República Oriental del Uruguay, T. I y II, Montevideo, 1903.

8 Chiaramonte, «El mito de los orígenes de la Historiografía Latinoamericana», Cuadernos del Instituto Ravignani, Instituto de Historia Argentina y Americana «Dr. Emilio Ravignani», Facultad de Filosofía y Letras, UBA, Buenos Aires, 1991; «El federalismo argentino en la primera mitad del siglo XIX», en Federalismos latinoamericanos: México, Brasil, Argentina, Buenos Aires, F.C.E, 1993 y «Finanzas públicas y política interprovincial: Santa Fe y su dependencia de Buenos Aires en tiempos de Estanislao Lopéz», en Boletín del Instituto de Historia Argentina Y Americana «Dr. E. Ravignani, $\mathrm{n} \circ 8$, Buenos Aires, F.C.E. y Fac. Filosofía y Letras, UBA, 1993, pp.77-116. 

EL EQUILIBRIO MUY INESTABLE DE LA CUENCA DEL PLATA ¿UN
CONFLICTO EN CRECIMIENTO?, 1828-1838.

El primer nivel de conflicto que se presentó luego de las revoluciones independentistas fue la disputa por el libre comercio entre los dos puertos principales y los del resto del Litoral de los ríos. Esta cuestión, como veremos, fue resolviéndose con rapidez en favor de los primeros.

Desde comienzo de la década de 1820 Buenos Aires y Montevideo lograron mantener su status de únicos puertos de ingreso y egreso de productos ultramarinos. Por ello, si bien en el contexto político se defendían los intereses locales representados por los Estados Provinciales o por las ciudades del interior, los de aquéllos se impusieron, claro que no sin generar durante bastante tiempo turbulencias políticas permanentes.

En 1824 se hizo evidente, a través de su política arancelaria, la ofensiva de los porteños con el fin de atraer los frutos de exportación hacia su puerto. A partir de entonces, sólo se cobró un gravamen al tabaco, la yerba mate y los cigarros, más un módico impuesto de «contribución directa» a todos los efectos, equivalente al 4 por mil del valor de aforo de las transacciones.

A lo largo de esa década, con las restricciones impuestas para el comercio ultramarino, el flujo desde las provincias hacia Buenos Aires fue creciendo y fortaleciendo el antiguo vínculo de intermediación. No obstante, a principios de 1830 la situación se tornó muy polémica, lo que abrió un «debate» en torno al papel que el puerto de Buenos Aires jugaba en relación al resto del espacio rioplatense.

Fue Pedro Ferré, el gobernador de la provincia de Corrientes, quien encabezó la protesta. Este planteaba varias cuestiones importantes en la política de la época, entre las cuales estaba el tema de las vinculaciones comerciales. Pero, a pesar de la clara antipatía y perjuicios que para las provincias del Litoral de los ríos significaba la posición del gobierno porteño, la propuesta de Ferré de permitir que otros puertos también realizaran el intercambio con ultramar, no logró reunir suficiente consenso y fuerza política para imponer los cambios requeridos ${ }^{9}$, por los cuales habría que esperar aún tres décadas.

\footnotetext{
9 La habilitación de otros puertos en el Litoral de los Ríos ahorraría muchos gastos a las provincias. «Circular del Sr. Ferré a los gobiernos del Interior», 13/4/1832, en Docu-
} 
En efecto, no obstante los postulados que emanaban del Pacto Federal ${ }^{10}$, en cuanto a buscar un pronto arreglo del país bajo un sistema federal, y llegar a un acuerdo sobre el comercio interior y exterior, la navegación y el cobro y distribución de las rentas generales, ello no se logró hasta la década de $1860^{11}$.

En tanto en la República Oriental del Uruguay, poco después de la independencia, —en marzo de 1829-, el gobierno expresaba su anhelo de que el puerto de Montevideo se convirtiera en el más importante, por lo cual decretaba:

1) liberación de derechos a los cueros introducidos al puerto de Montevideo, procedentes de puertos extranjeros; 2) los géneros y artículos extranjeros que se despachen por reexportación para puertos extranjeros del Uruguay y Paraná pagarán el 1\% y la mitad del eslingaje; y 3) no se permitirán esas operaciones en buques de más de 150 toneladas $^{12}$.

De este modo, aquí también se legislaba para atraer las exportaciones hacia Montevideo y para evitar la llegada directa del tráfico ultramarino al interior de los ríos.

Unos meses más tarde, durante la discusión de la primera ley de Aduana del Estado Oriental, hubo fuertes debates entre los representantes de la Asamblea Constituyente y Legislativa. Allí también se puede ver los diferentes intereses locales que tenían los representantes de Montevideo y de las ciudades de la costa del río Uruguay. Mientras el representante de Montevideo, Luis Lamas, se oponía a la habilitación de puertos en Maldonado, por su pobreza, y en Colonia,

mentos para la Historia Argentina, t. XVII, Relaciones interprovinciales. La Liga del Litoral (1829-1833), Buenos Aires, Instituto de Investigaciones Históricas, Facultad de Filosofía y Letras, UBA, 1922, p. 163.

10 El Pacto Federal de 1831 fue firmado por Buenos Aires, Santa Fe y Entre Ríos; posteriormente lo hizo Corrientes y más tarde se fueron sumando las restantes provincias para conformar de este modo la Confederación Argentina que rigió las relaciones interprovinciales hasta la caída de Rosas en 1852.

11 La provincia de Buenos Aires fue la que manifestó mayor desinterés por llegar a un acuerdo sobre estas cuestiones. Al respecto se puede consultar a Emilio RAVIGNANI, Asambleas Constituyentes Argentinas, t. VI.

12 Ariosto Gonzalez, Tratado de Derecho Aduanero Uruguayo, Montevideo, Facultad de Derecho, Universidad de la República, 1946, p. 191. 
Soriano y Paysandú, porque generarían contrabando, otros, como Antonino Costa, defendía la autorización de esos puertos ${ }^{13}$.

Pero, pese al alegato de algunos diputados y del propio Ministro de Hacienda, Francisco Muñoz, que sostenía que era necesario la apertura de los puertos del país, porque de esa manera el comercio montevideano extendería sus relaciones y aumentaría el comercio interior y exterior ${ }^{14}$, la situación de privilegio de Montevideo frente a los puertos del Litoral del Uruguay fue cada vez más evidente.

De esta manera, una vez consolidada la política de intermediación comercial con el interior, Buenos Aires y Montevideo perseguían los mismos objetivos: ser el principal interlocutor entre el Atlántico y el espacio mercantil de la cuenca del Plata. Ambos puertos pretendían estrechar al máximo los vínculos con el tráfico de cabotaje impidiendo el trato directo o a través de su rival con ultramar. En pos de alcanzar esa hegemonía desde comienzo de 1830 se agudizó la competencia y se intentó neutralizar al oponente con medidas de represalias impositivas.

El endurecimiento de la política comercial oriental para incrementar su participación en los mercados de cabotaje de ambas riberas del río Uruguay, se acelera con el decreto de noviembre de 1832 de balizamiento y circulación restringida de los ríos. A ello se sumaban las medidas que estimulaban la reexportación hacia puertos de dicho río y del Paraná y la prohibición en 1833 de introducir papel moneda de Buenos Aires.

El resultado más visible de estas medidas fue una inmediata reacción desde Buenos Aires, ya que las mismas eran negativas para su comercio con los pueblos uruguayos. En el editorial del principal diario comercial porteño «La Gaceta Mercantil» se exponía la cuestión afirmando que las políticas arancelarias orientales no solo eran arbitrarias y perjudiciales para Buenos Aires, sino que también habían generado incesantes clamores y daños a los habitantes de los centros costeros del río Uruguay por la subida de los precios y por la falta de estímulo que produjo a las «industrias» de estos lugares ${ }^{15}$. Si bien estos argumentos pueden haber sido parciales en favor de Bue-

13 Costa señalaba que Paysandú tenía derecho a usar su puerto y negárselo sería un despojo, agregando que favoreciendo a Montevideo se concedería privilegios a unos habitantes sobre otros. GoNZALEZ, [12], pp. 194-95.

14 Ibídem.

15 La Gaceta Mercantil, 24 de enero de 1832.

R. I., $1999, \mathrm{n}^{\circ} 215$ 
nos Aires, lo cierto era -como muestran los cuadros que presentamos más adelante- que tenían validez ya que el comercio fluvial uruguayo con los bonaerenses era de un volumen creciente, y esta política dictada desde Montevideo afectaba importantes intereses locales de Paysandú y Salto.

La respuesta del otro lado del Plata no se hizo esperar mucho tiempo; solo unos años más tarde, en 1835, la nueva ley de Aduana de Buenos Aires impuso una cuarta parte de recargo en los derechos a los efectos de ultramar que vinieran por transbordo o reembarque de cabos adentro. De esta manera la medida era funesta para el comercio de Montevideo con el Litoral de los Ríos y Buenos Aires.

El Gobierno Oriental protestó ante esta nueva situación. Su reclamo se fundaba básicamente en los vínculos de unión y pasado común que tenían ambos países. El Ministro de Hacienda de Buenos Aires respondió que si bien reconocía los argumentos orientales, el pedido de los mismos suponía un gran perjucio para los porteños, por lo cual no podía ser insensible a las pérdidas que sufriría el comercio de esta plaza ${ }^{16}$.

A raíz de los efectos que perseguía la ley de Aduana de Buenos Aires de 1835 , los diputados orientales discutieron medidas de represalia, si bien ninguno de los proyectos fue puesto en práctica por el Poder Ejecutivo, y como veremos, a partir de entonces se implementó un nuevo tipo de política comercial ${ }^{17}$.

Este período de 1828 a 1838 , en el que primaron los intentos de políticas represivas entre los principales puertos rioplatenses se cierra cuando los orientales dictaron en 1837 una nueva ley de Aduana. En ésta se liberalizaba el comercio de cabos adentro del Río de la Plata, se estipulaba que los efectos que hubieran pagado los derechos de introducción, los que salgan por transbordo y baleación para los puertos de cabos dentro serán libres de todo derecho. Esta nueva modalidad de libertad total pretendía a través de una nueva estrategia estimular el papel reexportador de Montevideo. Asimismo, esta legislación presentaba otro rasgo liberal, al habilitar también los puertos de Colonia, Soriano y Paysandú.

¿Qué éxito tuvieron las políticas comerciales de los dos grandes puertos entre 1828 y 1838 ?. Si analizamos el comportamiento del

\footnotetext{
16 Ibídem, 30 de abril de 1836.

17 GonZaLeZ, [12], pp. 197-199.
} 
flujo comercial arribado al puerto de Buenos Aires constatamos que la franja oriental del río Uruguay comenzó a mostrarse como una de las más dinámicas de la región. También se verifica que pese a los intentos de Montevideo por canalizar los frutos exportables de su propio hinterland rural, no logró impedir la fuerte vinculación que el mismo tenía con Buenos Aires.

CUADRO 1: PORCENTAJE QUE REPRESENTAN LOS CUEROS VACUNOS Y BAGUALES, LA LANA Y EL TASAJO PROVENIENTES DE LA COSTA ORIENTAL DEL RIO URUGUAY EN LA CANTIDAD TOTAL ARRIBADA A BUENOS AIRES*

\begin{tabular}{||c|c|c|c|c||}
\hline \hline AÑOS & $\begin{array}{c}\text { CUEROS } \\
\text { VACUNOS }\end{array}$ & $\begin{array}{c}\text { CUEROS } \\
\text { BAGUALES }\end{array}$ & LANA & TASAJO \\
\hline 1831 & 8,7 & 25 & 0 & 71,2 \\
\hline 1832 & 7,5 & 31,9 & 1,07 & 60,7 \\
\hline 1833 & 12,3 & 50 & 17,2 & 61,5 \\
\hline 1834 & 11,6 & 59 & 4,9 & 64 \\
\hline 1835 & 20,4 & 23 & 8,2 & 61 \\
\hline
\end{tabular}

* En este flujo mercantil no está contabilizado lo que llega desde la campaña bonaerense. Fuente: ver Apéndice.

No obstante la capacidad que mostraba el puerto de Buenos Aires de captar una buena parte del flujo mercantil del Litoral de los ríos y de la costa oriental del Uruguay, durante el trienio 1835-1837, Montevideo logró superar las exportaciones de cueros baguales y tasajo efectuadas por Buenos Aires ${ }^{18}$.

De este modo, hasta fines de la década de 1830, a pesar de los intentos de hegemonía, se mantenía un relativo equilibrio entre Montevideo y Buenos Aires en el manejo del comercio rioplatense.

18 Así, por ejemplo entre 1835-1837, Buenos Aires exportaba 1.980 .550 cueros vacunos, 86.280 cueros baguales, 427.594 arrobas de lana y 448.473 quintales de tasajo. Mientras que del Uruguay salían 1.551.296 cueros vacunos, 113.000 cueros baguales, 102.000 arrobas de lana y 825.430 quintales de tasajo. (ver cuadros 1 a 4 en el Apéndice)

R. I., $1999, \mathrm{n}^{\circ} 215$ 
EL DESEQUILIBRIO SE ACELERA: GUERRAS Y BLOQUEOS COMERCIALES, 1839-1852

La región rioplatense se ve sacudida, en el período que va desde mediados de la década de 1830 hasta los inicios de la de 1850, por serios conflictos internos y externos. Durante estos años se produce el enfrentamiento - dando comienzo a la llamada «Guerra Grande»entre los caudillos orientales Oribe y Rivera, apoyados, el primero por Rosas y algunos jefes federales del Interior, y el segundo, por los unitarios porteños exiliados en Montevideo, buena parte del federalismo del Litoral —en especial, los correntinos, desencantados con el rosismo-, y potencias extranjeras, como por ejemplo, Francia. Precisamente, la tirantez de las relaciones entre el gobernador bonaerense y esta última desemboca en el primer gran bloqueo europeo al puerto de Buenos Aires. Pocos años después, en 1845, se produce el segundo, al cual se suma Gran Bretaña.

Es decir que, además de la vieja puja de los interes locales rioplatenses y de diferentes fracciones políticas, ahora se agregaba la de los británicos y franceses que pretendían obtener ventajas comerciales en la navegación de los ríos interiores de la cuenca del Plata, provocando, entonces, significativas alteraciones en los vínculos mercantiles de ambos puertos del Plata.

En 1838 Francia exigió al gobierno porteño que otorgara a sus súbditos residentes en Buenos Aires los mismos privilegios que gozaban los británicos. La negativa de Rosas significó la excusa para iniciar el bloqueo, lo cual parecería haberle producido al gobernador escaso interés en los resultados que esto traería para el comercio rioplatense.

La situación dejó desconcertados a los dirigentes de las provincias. Frente a las noticias extraoficiales de los eventos el gobernador delegado de Santa Fe, Domingo Cullen, sorprendido por los rumores que circulaban, escribió a Rosas en busca de una confirmación

Según parece este bloqueo será extensivo a todos los puertos de la República; [me cuentan] sobre la alta que tal suceso ha producido en los efectos de ultramar. A pesar de la reputación que merece la persona que firma esta carta, yo no he podido dar crédito por que no puedo persuadirme que, siendo esto efectivo, no viniese ganando horas una circular a 
los gobiernos litorales avisando de tal negocio, entre otras razones para que no sean perjudicadas en su comercio... ${ }^{19}$.

De esta manera quedaba expresada la impotencia de las provincias del Litoral ante la política ejercida por Rosas, el cual apenas se dignaría a enviar tardíamente una circular en la cual demandaba la aprobación sin más trámite de las gestiones de su gobierno con el cónsul francés.

Lo cierto fue que, a pesar de las espectativas de una rápida solución que tenían los dirigentes del Litoral y algunos miembros de la legislatura porteña, los cuales alertaban que el bloqueo era la ruina del país y del gobierno ${ }^{20}$, el gobernador bonaerense se mantuvo en una posición innamovible frente a los reclamos hasta el levantamiento del mismo a fines de 1840 .

Frente al fracaso de neutralizar la influencia que el puerto de Buenos Aires ejercía en la cuenca del Plata, en 1841 el líder oriental Fructuoso Rivera intentó un acercamiento aún más directo con Gran Bretaña. La idea era darle ventajas exclusivas, para lo cual se le ofrecía una factoría en el río Uruguay que fuera depósito para las producciones naturales y manufacturadas del imperio británico. $\mathrm{Si}$ bien la misma fue rechazada, la apertura de los ríos seguía siendo una apetencia muy concreta para la mayoría ${ }^{21}$.

En 1845 nuevamente las potencias navales europeas bloquearon el puerto de Buenos Aires. En esta oportunidad, mucho más que en la primera, se pretendía alterar la dirección que tenían los flujos mercantiles y el papel que jugaban los dos puertos ultramarinos.

El análisis del tráfico arribado a Montevideo entre los años 18461852 , muestra que el volumen del comercio creció considerablemente en los dos primeros años -en concordancia con el férreo bloqueo a los porteños- para luego caer estrepitosamente hasta 1850 cuando logró una modesta recuperación. Aquél incremento se debió a que los productos de exportación de Corrientes y Entre Ríos, junto

19 José Luis Busaniche, El bloqueo francés de 1838 y la Mision Cullen. Federalismo y rosismo. Buenos Aires, Ed. Huarpes, 1945, p. 32.

20 Los miembros de la Legislatura pensaban que mientras el bloqueo se mantuviera no se podría exportar y aumentarían los precios de los bienes importados, generando un gran descontento tanto entre los opositores y como entre los partidarios del gobierno. BUSANICHE, [19], p. 32.

21 Mateo Magariños de Mello, La misión Florencio Varela a Londres (1843-44), Montevideo, 1944.

R. I., $1999, \mathrm{n}^{\circ} 215$ 
a la producción de la campaña oriental, que habitualmente tenían como destino Buenos Aires, se reorientaron hacia Montevideo, precisamente a causa del bloqueo anglo-francés, pero cuando éste se hizo muy débil y luego fue levantado, los productos pecuarios de estas áreas retornaron a su ruta habitual hacia el puerto bonaerense.

En cuanto a los porcentajes de participación de cada una de esas zonas en el comercio de cabotaje hacia Montevideo durante esos años, es sumamente difícil poder establecer proporciones exactas. La dificultad radica en que gran parte de los productos exportados desde Entre Ríos salió sin ser registrada por las aduanas de esa provincia, debido a que el gobierno de Urquiza intentó encubrir este tráfico para no tener un grave conflicto con el gobierno de Buenos Aires que había prohibido el comercio con Montevideo a todas las provincias de la Confederación Argentina.

No obstante lo señalado, el tráfico desde Entre Ríos fue intenso durante los dos primeros años del bloqueo, en especial a partir de 1846 ya que el gobernador delegado de la provincia, Antonio Crespo, autorizó el arribo de numerosos barcos de «banderas amigas». Ante esa circunstancia la administración rosista intimó a terminar con ese comercio y a cumplir con las órdenes dictadas por Buenos Aires a la Confederación en noviembre de 1845. Estas establecían que solo se podía permitir la introducción de mercancías procedentes de buques nacionales, con exclusión de toda otra bandera, incluyendo los que se trasbordaban en Montevideo. Solo se dejaba la posibilidad de exportar por aquel puerto las carnes saladas en barcos argentinos que hubieran traído productos importados forzando de esa manera el bloqueo ${ }^{22}$. A pesar de la respuesta favorable que Urquiza remitió a Buenos Aires sobre el cumplimiento de estas instrucciones, los datos indican que no se respetaron y que se permitió al comercio entrerriano realizar todos los negocios prósperos que la coyuntura le ofrecía.

Respecto a los bienes arribados a Montevideo en los convoyes que fueron escoltados por las fuerzas navales anglo-francesas, las cuales forzaron la navegación por el Paraná durante un breve lapso, resulta difícil discernir con precisión la proporción que les corres-

22 Correspondencia de Felipe Arana al Gobernador Urquiza, 1/11/1846. Archivo Histórico de la Provincia Entre Ríos (en adelante AHPER), División Gobierno II, Carpeta 7, Legajo 14. 
ponde a Corrientes y al Paraguay ${ }^{23}$. Asimismo, los registros que se publican en el Comercio del Plata de Montevideo aclaraban que sobre el movimiento comercial en el Río de la Plata y sus afluentes

no es posible presentar un estado como el de la navegación de ultramar, porque la situación política del país obliga generalmente a ocultar su procedencia y destino de las expediciones ... sin embargo para que se pueda juzgar en el exterior de la importancia del cabotaje de nuestra situación actual, solo diremos que es el único medio por el cual nuestro mercado se provee de productos del país.... [También destacaba que] el contrabando que se hace desde los puertos de la costa argentina obliga con frecuencia a disfrazar y ocultar el mayor número de las transacciones, especialmente en los artículos del Brasil, que por su crecido consumo en aquellos mercados, son los que en mayor cantidad se remiten. Colocados en situación tan embarazosa reduciremos pues nuestros informes ...24.

Teniendo en cuenta la parquedad de las fuentes, solo estamos en condiciones de presentar una estimación del origen de los cueros vacunos para 1846 cuando se discrimina con mayor precisión, y que se podría tomar también como indicador general del movimiento de estos años. Mientras que a los cueros vacunos correntinos-paraguayos les corresponde un 35\%, los de Entre Ríos y las campañas de la Banda Oriental y Buenos Aires alcanzan un 65\%

En cuanto a la composición del tráfico observamos un amplio predominio de los cueros secos y salados, los cuales acumulan el $84 \%$ del valor comerciado, seguidos por la lana con el $5 \%$, el sebo $4 \%$, la carne salada $3 \%$, los cueros de bagual $3 \%$ y las plumas de avestruz y astas $1 \%$.

Respecto a las exportaciones ultramarinas de Montevideo para los mismos años, muestran que su dinámica fue absolutamente dependiente de los volúmenes de ingresos de cabotaje - los cuales a su vez estuvieron condicionados, como anticipamos, por la contunden-

23 En esas operaciones tomaron parte 20 barcos de ultramar que transportaron 3229 toneladas y 75 buquecillos del cabotaje del Uruguay y de las provincias del Paraná con 3704 toneladas. Dichos bienes alcanzaron un valor total de 889.805 pesos plata. Comercio del Plata, Revista Comercial del 6/7/1846.

24 Ibidem, primer trimestre de 1847.

25 Además deben haber arribado una cantidad desconocida de cueros procedentes desde las provincias interiores, especialmente Córdoba y Santa Fe.

R. I., 1999, n. $^{\circ} 215$ 
cia que lograron los europeos en el bloqueo impuesto a Buenos Aires-, por lo cual tuvieron un gran crecimiento en 1846-1847, una brusca caída entre 1848-1850 y una leve recuperación hasta 1853. La composición de las mismas fue prácticamente idéntica a la del comercio de cabotaje.

Por su parte, el puerto de Buenos Aires logró consolidar su papel hegemónico en el Río de la Plata a partir de la década de 1840, excepto durante los años del segundo bloqueo.

El análisis de la dinámica del comercio que desde el Interior se dirigía al puerto de Buenos Aires nos ayuda a ponderar el grado de articulación de todo el espacio rioplatense con la capital de la Confederación durante el lapso rosista. De las cuatro regiones en que se dividió el espacio, la campaña de Buenos Aires, principalmente, y el Litoral fueron las que más aportaron en la composición total del flujo mercantil, mientras las otras dos regiones, la Central y Cuyo, registraron bajos niveles de participación, especialmente en el último de los casos.

Dentro del Litoral, Entre Ríos se consolidó como la provincia más pujante, de la mano del área que se recuesta sobre el río Uruguay. El dinamismo observado en la misma, sumado al que se desarrolló en la orilla de enfrente, territorio de la antigua Banda Oriental, permite concluir que el eje del tráfico comercial rioplatense se trasladó desde el Paraná —donde se ubicó hasta fines de los 30 - al Uruguay ${ }^{26}$.

26 Sobre la cuestión se puede consultar el trabajo de RosAL, «El Interior frente a Buenos Aires: flujos comerciales e integración económica, 1831-1850», en Secuencia, nํ 31, México, Instituto Mora, ene.-abr. de 1995, pp. 51-111. 
CUADRO 2: PORCENTAJE QUE REPRESENTAN LOS CUEROS VACUNOS Y BAGUALES, LA LANA Y EL TASAJO PROVENIENTES DE LA COSTA ORIENTAL DEL RIO URUGUAY EN LA CANTIDAD TOTAL ARRIBADA A BUENOS AIRES*

\begin{tabular}{||c|c|c|c|c||}
\hline \multirow{2}{*}{ AÑOS } & $\begin{array}{c}\text { CUEROS } \\
\text { VACUNOS }\end{array}$ & $\begin{array}{c}\text { CUEROS } \\
\text { BAGUALES }\end{array}$ & LANA & TASAJO \\
\hline 1841 & 17,8 & 38,9 & 4,2 & 97,96 \\
\hline 1842 & 14 & 15,6 & 4,6 & 90,45 \\
\hline 1843 & 41,5 & 39,4 & 9,7 & 99,96 \\
\hline 1844 & 47,6 & 3,3 & 28,3 & 100 \\
\hline 1845 & 46,9 & 0,1 & 27,8 & 0 \\
\hline 1846 & 2,8 & 0 & 0 & 0 \\
\hline 1847 & 2,6 & 0 & 0 & 0 \\
\hline 1848 & 34,6 & 7,6 & 4,4 & 87 \\
\hline 1849 & 32,2 & 46,4 & 13 & 90,17 \\
\hline 1850 & 31,2 & 52,5 & 6,2 & 89,86 \\
\hline
\end{tabular}

* Tampoco aquí se han consignado los envíos de la campaña de Buenos Aires.

Fuente: ver Apéndice.

Los productos pecuarios fueron los principales componentes del flujo desde el interior, y si bien se destacaron en el mismo los cueros vacunos, no se puede soslayar la presencia que tuvieron los cueros baguales, la lana y el tasajo en la plaza porteña. Los envíos de estos cuatro productos, junto a los provenientes de la campaña bonaerense, conformaron el grueso de las exportaciones a través del puerto de Buenos Aires ${ }^{27}$.

Si comparamos los envíos argentinos hacia el exterior con la performance del principal puerto uruguayo, se ve - como demuestra nuestra serie - una clara superioridad de Buenos Aires, la cual exportó el $66 \%$ de los cueros vacunos en 1841 y el 55\% en 1842. Más tarde, durante el quinquenio 1848-1852, sobre casi trece millones de cueros exportados, a esta última le correspondió el $89 \%$, relegando de manera notable al puerto de Montevideo.

27 Sobre el tema se puede consultar el trabajo de Rosal, «La exportación de cueros, lana y tasajo a través del puerto de Buenos Aires entre 1835 y 1854 », en XV Jornadas de Historia Económica, Tandil, 1996.

R. I., $1999, \mathrm{n}^{\circ} 215$ 
En resumen, hacia mediados de siglo en el espacio mercantil rioplatense se dieron algunas alteraciones coyunturales. El bloqueo del puerto de Buenos Aires entre 1845-1848 afectó la vinculación comercial de buena parte del Litoral de los Ríos y reorientó las exportaciones pecuarias hacia la capital uruguaya. En algunos casos, como el de Entre Ríos, uno de los principales aliados de Rosas, la reorientación se dio a pesar de las amenazas emanadas desde el gobierno porteño. Por su parte, Corrientes y el Paraguay - permanentes rivales de la política económica rosista que impedía la libre navegación de los ríos - aprovecharon esta situación para conectarse directamente con Montevideo. Asimismo, los bienes de la zona costera de la campaña oriental, que habitualmente eran captados por Buenos Aires, encontraron salida en el mercado montevideano.

La nueva situación alteró notablemente el desempeño de los dos puertos, al punto que Montevideo logró un predominio transitorio durante los años 1846 y 1847 al exportar $68 \%$ de los productos rioplatenses, mientras a Buenos Aires le correspondió el resto. Esta situación fue muy breve, pues aun antes de ser levantado el bloqueo, la plaza comercial porteña ya mostraba una notable capacidad para restablecer los antiguos vínculos de supremacía mercantil en el Río de la Plata. (ver cuadros 1 a 4 en el Apéndice)

\section{LOS NEGOCIOS EN EL ESPACIO MERCANTIL RIOPLATENSE}

El flujo mercantil rioplatense tuvo una importante vitalidad en la primera mitad del siglo XIX; aquélla se expresa claramente en el permanente crecimiento de la exportación de cueros vacunos, la cual pasó de unas 850.000 unidades anuales durante el quinquenio 18151819 a alrededor de 2.560 .000 cueros por año entre 1848 y 1852 .

Como vimos, hasta fines de los 30 Buenos Aires y Montevideo mantuvieron un relativo equilibrio en cuanto a la captación de los bienes de exportación que llegaban desde las regiones interiores del espacio rioplatense y su posterior exportación. Pero, a partir de la década de 1840 y no obstante los enfrentamientos militares y el bloqueo anglo-francés se fue consolidando la supremacía del puerto de Buenos Aires, el cual a mediados de siglo XIX exportaba regularmente el $70 \%$ de los productos pecuarios rioplatenses, correspondiéndole el resto a Montevideo. Esta situación se mantuvo hasta el 
decenio de 1880 , mostrando que las ventajas obtenidas por la primera no se debían a una coyuntura efímera.

\section{GCO. I: EXPORTACIONES DE CUEFOS VAC. BS.AS. Y MONTEVIDEO}

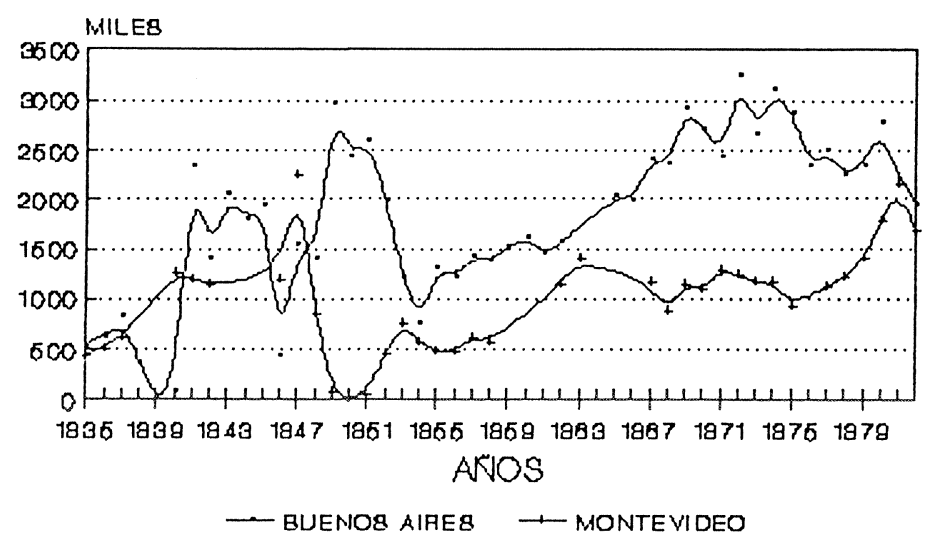

\section{GCO. II: EXPORTACIONES DE} LANA DE BS.AS. Y MONTEVDDEO

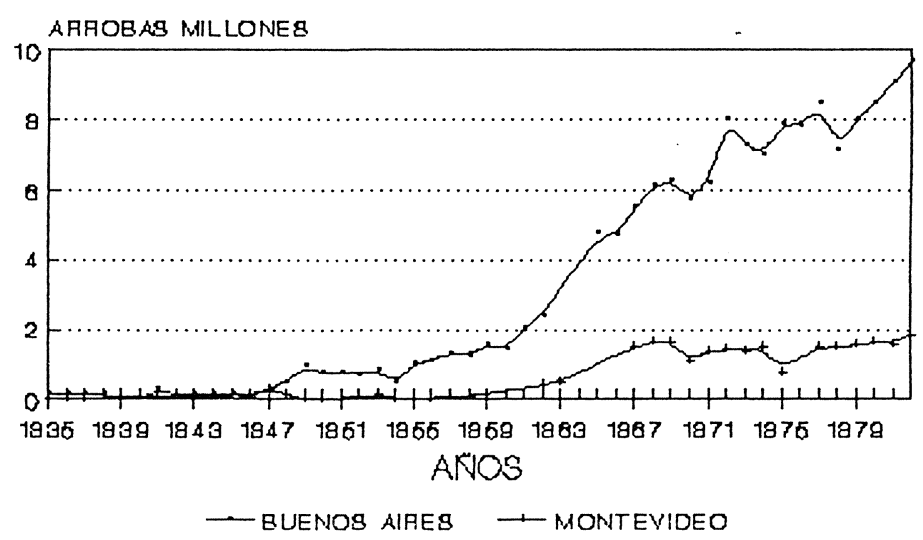

R. I., $1999, \mathrm{n}^{\circ} 215$ 
La consolidación de ese rol preponderante de Buenos Aires se basaría un una conjunción de factores claves que le permitiría hacer buenos negocios. Entre los principales se encuentra la ventaja de contar con un hinterland ganadero propio que abastecía su puerto hacia mediados de siglo con alrededor de 1 millón de cueros anuales, mientras que Montevideo en muchas ocasiones no lograba siquiera captar una buena parte de la producción pecuaria de su campaña (de la cual se beneficiaron los porteños). Esa importante riqueza se debió a que desde 1820 la provincia de Buenos Aires comenzó un proceso de expansión de su frontera productiva que implicó la puesta en producción de nuevas tierras, la absorción de mano de obra rural y el crecimiento del stock ganadero. Este proceso, que no demandó mucha inversión de capital ni avances técnicos, en pocas décadas le permitió a los bonaerenses contar con un nivel de producción muy superior al de sus estados vecinos ${ }^{28}$.

Otro factor significativo fue que Buenos Aires logró captar los principales flujos comerciales procedentes, como señalamos, de la zona rural de la Banda Oriental y, además, los del Litoral de los Ríos y Córdoba. De esa manera concentró un importante volumen de bienes exportables, lo que habría sido decisivo para atraer al comercio extranjero hacia su puerto. Para este último era fundamental vincularse con aquellos mercados que tuvieran buena capacidad de compra y de pagos. Un mercado era dinámico sólo cuando contaba con suficientes bienes de retorno para saldar las operaciones. De esta manera, además del oro y la plata, la concentración de productos pecuarios eran un excelente medio para pagar buena parte de los bienes importados.

También en el comercio interno las operaciones mercantiles entre particulares o entre éstos y el estado se saldaban con bienes de exportación y, en menor medida, dinero. Para ilustrar lo expresado, podemos citar las cuentas de importantes comerciantes que operaban en estas tierras, tales como Hugo Dallas, Rams y Rubert y Félix Castro. El primero, de nacionalidad británica, firmó con Francisco Delgado varios convenios en los cuales se comprometían a intercambiar cierto tipo de productos a un precio determinado y en un período establecido. La rendición de cuentas del año 1819, por ejemplo, muestra que Dallas envió a Delgado, a lo largo de dicho año y en

28 HALPERIN DoNGHI, [5] «La expansión ganadera...». 
numerosos remesas, tabaco negro, vino carlón y caña por un valor de 36.837 pesos plata. Estos bienes importados fueron saldados en un $80 \%$ por productos pecuarios (cueros, sebo y crin) y solo en un $15 \%$ en pesos, más un $5 \%$ en bonos ${ }^{29}$.

Un mecanismo similar de intercambio utilizaron los estados provinciales para abastecerse de bienes. Las operaciones realizadas en 1849 entre el gobierno de Entre Ríos y la casa comercial Rams y Rubert echan luz sobre la cuestión. En dicho año los entrerrianos recibieron pólvora, madera, muebles y libros, entre otras mercancías, por un valor de 70.157,5 pesos papel. Esta deuda no solo fue saldada íntegramente con la remesa de cueros vacunos, sebo y carne salada, sino que debido a la magnitud de los envíos de bienes de retorno, el estado provincial tuvo a fin del año un saldo favorable de 46.810,6 pesos papel $^{30}$.

La ventaja que representaba tener bienes de retorno era percibida muy claramente por los montevideanos cuando señalaban que

las entradas de buques de ultramar [a Montevideo] ha sido muy limitado, la mejoría que han tenido los precios de Buenos Aires sobre los artículos del mediterráneo ha contribuido a que los buques sigan para allá, a pesar del alza que han tenido los precios es siempre inferior a los que aquí obtendrian, pero la rehusan los especuladores por la esperanza del mayor lucro que pueden obtener con los productos que otros puertos exporten ${ }^{31}$.

Pero la cuestión era más compleja; también tuvo cierta importancia la disponibilidad de otro tipo de medios de pagos; nos referimos al uso de un mix para saldar las operaciones, el cual se basaba en una combinación de dichos medios que incluyó, como ya mostramos, a los bienes pecuarios, el papel moneda y los bonos, y también las letras.

Creemos que los comerciantes porteños habrían estado en una posición más ventajosa que los de otras plazas, ya que también manejaron una amplia cartera de negocios que contemplaba el uso de las mercancías y los papeles, conectando la plaza mercantil con la financiera. Por ello la expansión del papel moneda, los bonos y las

29 Archivo del Banco de la Provincia de Buenos Aires, Archivo comercial de Hugo Dallas, legajo 2, carpeta 24

30 AHPER, Hacienda, serie 1, carpeta 130, legajo 2.

31 Comercio del Plata, Revista Comercial del 27/2/1850. 
letras, a pesar de su depreciación, se habrían convertido en medios de pagos que aceleraron la marcha de las operaciones.

Las letras y los bonos públicos podían sufrir un descuento sobre su valor nominal según la solvencia que tuviera el deudor. A su vez, los bonos públicos solían ser utilizados para pagar los impuestos a las importaciones o las exportaciones en las aduanas, e, incluso, para saldar las operaciones comerciales y financieras de los estados provinciales. Los negocios del gobierno entrerriano con Félix Castro ejemplifican lo señalado. El Estado había adquirido a lo largo de 1823 y 1824 una serie de bienes destinados a las tropas y a su aparato administrativo. A raíz de ello acumuló una deuda de 8.800 pesos plata que cubrió con tres remesas de bonos. El valor nominal de los mismos era de 10.000 pesos, pero sufrieron un descuento de 1.200 pesos, dado que se cancelarían a los 4,8 y 12 meses. Luego estos bonos eran usados por Castro como medio de pago para realizar nuevas operaciones mercantiles ${ }^{32}$.

En síntesis, el predominio mercantil de los porteños en los circuitos comerciales rioplatenses parece haber impedido el crecimiento de un vínculo comercial de envergadura similar entre el Litoral y la plaza de Montevideo. Esta situación habría dificultado realizar el anhelo montevideano de que

los acontecimientos próximos abran otros mercados, y que ellos ofrezcan confianza al especulador. Si estas confianzas se realizan, pronto reaparecerá el movimiento, y todos los artículos que hoy no tienen aplicación, por el reducido consumo de la capital y la limitada extracción al Uruguay y Entre Ríos entrarán en demanda, serán reexportados con ventaja, y sus retornos, serán la base de nuevas y más valiosas empresas $^{33}$.

De este modo, pese a las coyunturas de continuos enfrentamientos políticos, de permanentes reclamos de libre navegación de las

32 AHPER, Hacienda, serie 1, carpeta 9, legajo 26. Sobre el tema de las diversas formas de pago y de crédito en otras regiones de Hispanoamérica se puede consultar, entre otros, a Francisco Javier Cervantes Bella, «Las letras de cambio en Puebla (1846-1856). Un estudio a partir de los protestos», en SILVA RIQUER y Leonor LuDLOw (comp.), Los negocios y las ganancias; de la colonia al México moderno, México, Instituto Mora e Instituto de Investigaciones Históricas de la UNAN, 1993. pp. 60-82.

33 Comercio del Plata, Gacetilla Mercantil del mes de febrero de 1846.

R. I., $1999, \mathrm{n}^{\circ} 215$ 
provincias del Litoral de los ríos, de los bloqueos navales, y de su situación de desventaja geográfica con respecto al puerto de Montevideo, Buenos Aires fue consolidando luego de las décadas de 183040 su supremacía político-económica. Para ello sus poderosos vínculos comerciales fueron un factor clave en el basamento de la larga hegemonía que esta provincia impuso a todo el espacio rioplatense en el siglo XIX.

\section{CONCLUSIONES}

El estudio de los vínculos mercantiles de la cuenca del Plata nos muestra que la creciente masa de bienes pecuarios de exportación hacia los mercados atlánticos fueron comercializados por los puertos de Buenos Aires y Montevideo. Desde la creación del Estado Oriental hasta fines de los 30 las exportaciones de ambas plazas parecen haber mantenido una cierta paridad, pero desde la década de 1840 en adelante - salvo en la coyuntura muy especial del bloqueo anglo-francés - fue evidente la preponderancia de Buenos Aires. Esta situación fue clave para mantener la hegemonía porteña sobre el resto del territorio, la cual se basaba en múltiples aspectos: la notable expansión y control de su campaña ganadera, el manejo de un volumen muy considerable de bienes de retorno para saldar las importaciones y la disponibilidad de medios financieros y de pagos para las operaciones del comercio interior y exterior.

De esta manera, merece ser relativizada la hipótesis de que hasta 1880 los dos puertos rioplatenses fueron vías alternativas similares para el ingreso y egreso de mercancías, pues el estudio de la dinámica de los flujos nos muestra que Buenos Aires fue acrecentando una situación de privilegio que no solo le permitió ganancias a corto plazo sino que le habría posibilitado estar en mejor forma para ser la principal beneficiaria del proceso de modernización de la segunda mitad del siglo XIX. Por ello, si Buenos Aires incrementó en dicho período su importancia en el Río de la Plata, habría que preguntarse si no fue en buena parte a causa de sus logros en las primeras seis décadas del siglo, que habrían tenido entre otras consecuencias la atracción de las inversiones extranjeras, la construcción de mejores puertos y el tendido del ferrocarril. 


\section{APÉNDICE}

\section{FUENTES UTILIZADAS PARA ELABORAR LAS SERIES DE COMERCIO}

En el análisis del comercio exterior de Buenos Aires y Montevideo, hemos utilizado diferentes fuentes -éditas e inéditas- que nos han posibilitado construir una larga serie -si bien con algunas interrupciones- sobre la salida de los principales bienes pecuarios de estas regiones, tales como los cueros vacunos y baguales, la lana y el tasajo, los cuales constituían el grueso de las exportaciones rioplatenses.

Creemos que la serie construída, que abarca desde 1815 a 1882, significa un aporte para el estudio comparativo del comercio exterior del Río de la Plata. En función de poner en contacto los datos de ambas plazas comerciales los expresamos en cantidad para que el cotejo pueda ser más evidente.

\section{a) fuentes para Buenos Aires}

Para el lapso 1815-1820 nos servimos de los datos consignados por Rodolfo Merediz $^{34}$ y para 1822,1825 y 1829 , de los de Woodbine Parish ${ }^{35}$. El año 1830 fue reconstruído a través de una fuente inédita, los libros de la «Salida Marítima» conservados en el Archivo General de la Nación y constituídos por los Permisos de embarque ${ }^{36}$. El período 1835-1840 fue estudiado a través de la consulta del Registro Oficial de la Provincia de Buenos Aires ${ }^{37}$. Nuevamente recurrimos a una fuente inédita, también del citado Archivo, para obtener las cifras del comercio exterior porteño entre 1840 y junio de 1848 ; nos referimos a los legajos de «Salida», compuesta por los mencionados Permisos de Embarque ${ }^{38}$. Una vez más, Parish brinda detalles sobre las exportaciones entre julio de 1848 y junio de

34. Rodolfo MEREDIZ, «Comercio de frutos del país entre Buenos Aires y mercados europeos entre 1815 y 1820», en Trabajos y Comunicaciones, n 16, La Plata, Facultad de Humanidades y Ciencias de la Educación, Universidad Nacional de La Plata, 1966, p. 150.

35 Woodbine PARISH, Buenos Aires y las provincias del Río de la Plata, Buenos Aires, Hachette, 1958, p. 511.

36 Archivo General de la Nación (en adelante AGN), Salidas Marítimas, 1830, III: 22 11-10/14 y 23-1-1 (sobre 771 Permisos de embarque, cada uno de los cuales fueron considerados como una operación y bajo esta denominación fue consignada en el trabajo); por medio de los citados permisos se pedía autorización para cargar los diversos productos y en ellos se registraban los derechos de «salida» que debía pagar cada mercancía (los cueros vacunos - secos, salados, de desecho, etc.-, al igual que los baguales y cueros de becerro, pagaban un peso; los nonatos, dos reales; el tasajo, las astas, la cerda, el sebo en rama, las pieles de nutria, etc., el cuatro por ciento $(4 \%)$ del aforo de dichos productos; y la lana, los cueros de carnero y el sebo derretido, estaban libres de derechos).

37 Registro Oficial de la Provincia de Buenos Aires, 1836-1841.

38 AGN, División Nacional, Sección Contaduría, Receptoría, Cargo y Data, Cargo, Sali$\mathrm{da}, \mathrm{n}^{\text {os }} 23-94,1840$-junio de 1848, Sala III: 24-5-5 a 25-5-7; se ficharon y analizaron 10.019 Permisos de Embarque. Estos datos fueron extraídos de la ponencia de RoSAL, [27], cuadro 1. 
185439. La información para 1855-1862, publicada por Haydée Gorostegui de Torres, corresponde a guarismos que van desde el $1^{\circ}$ de noviembre de 1854 al 31 de octubre de $1862^{40}$. Por último, las cantidades del lapso 1865-1882 fueron investigados por José Carlos Chiaramonte ${ }^{41}$.

Respecto a la elaboración de los cuadros 1 a 4, en donde se compara la salida de los cuatro productos mencionados a través de los puertos de Buenos Aires y Montevideo, es necesario puntualizar algunas observaciones. Los cueros están expresados en unidades, la lana en arrobas (@) y el tasajo en quintales (qq.). Los cueros vacunos y baguales incluyen secos y salados. Los fardos y bolsones de lana -mencionados por Parish- se estimaron en 35 @; a su vez,la bolsa -que aparece, al igual que los fardos, en la obra de Gorostegui de Torres-, se estimó en 5 @. Las toneladas de lana y tasajo -tal como son consignadas en el libro de Chiaramontefueron convertidas en @ y qq., respectivamente.

En cuanto al estudio de las «entradas terrestres» (los productos que desde el interior del espacio rioplatense se dirigían hacia Buenos Aires), hemos realizado un cruce de diversas fuentes, conservadas, en su mayor parte, en el Archivo General de la Nación, en donde se destacan los Manifiestos de Aduana, los Libros de Casilla de Resguardo de Aduana, los libros de Contribución Directa y los legajos de la Receptoría General, Cargo y Data, Sección «Contribución Directa», a las que debemos sumar el Registro Oficial de la Provincia de Buenos Aires, lo cual nos ha permitido obtener una serie representativa de dicho tráfico a través, fundamentalmente, de los datos brindados por los Manifiestos que presentaban los consignatarios de Buenos Aires en la Aduana porteña para retirar las mercancías ${ }^{42}$.

\section{b) fuentes para Montevideo}

Para el período 1815 a 1819 hemos utilizado los datos del citado Merediz ${ }^{43}$. El año 1829 ha sido analizado a través de los «apuntes» recopilados por Lamas ${ }^{44}$ y

39. PARISH, [35], pp. 512-517 y 622.

40 Haydée GOROSTEGUI DE TORRES, Argentina. La organización nacional, Historia Argentina, v. 4, Buenos Aires, Paidós, 1972, p. 44.

41 ChIARAmONTE, Nacionalismo y liberalismo económicos en Argentina, 1860-1880, Buenos Aires, Hyspamérica, 1986, p. 38.

42. En tales manifiestos se asentaba el valor de la «contribución directa», impuesto que alcanzaba el $4 \%$. (cuatro por mil) del total de los precios de aforo de los productos; cada manifiesto en cuestión fue considerado como una operación y bajo esta denominación fue consignada en nuestro trabajo. A partir del cruce de las fuentes mencionadas hemos registrado 34127 operaciones entre 1822 y 1850 . Al respecto se pueden consultar los siguientes artículos: RoSAL, [26]; SCHMIT, [2]; y SCHMIT y ROSAL, [2]. Dichos trabajos fueron publicados también -con iguales o similares títulos y contenidos- en RosAL y SCHMIT, Comercio, mercados e integración económica en la Argentina del siglo XIX, Cuadernos del Instituto Ravignani, n 9, Buenos Aires, Facultad de Filosofía y Letras, Universidad de Buenos Aires, 1995.

43 Merediz, [34], p. 147.

44. Horacio ARREDONDO, «Los apuntes estadísticos de Andrés Lamas», en Revista del Instituto Histórico y Geográfico del Uruguay, t. VI, n 1, Montevideo, año 1928, pp. 25-195.

R. I., 1999, n. $^{\circ} 215$ 
1830 fue tomado de los informes comerciales del periódico La Gaceta Mercantil de Buenos Aires ${ }^{45}$. Nuevamente, para el lapso 1835-1842, seguimos la información brindada por Lamas ${ }^{46}$. El período 1846-1854 ha sido reconstruído por medio de los informes comerciales del periódico Comercio del Plata_de Montevideo, con los cuales, además, hemos establecido el origen y cantidad de los productos que llegaban al puerto ${ }^{47}$. Los años 1855 a 1858 fueron estudiados a través de las cifras de Acevedo ${ }^{48} \mathrm{y}$, finalmente, para 1862 a 1882 empleamos los guarismos publicados por Barran y Nahun ${ }^{49}$.

Por último, debemos aclarar que en las citadas fuentes se basan, también, el cuadro 5 y los gráficos del trabajo.

\section{CUADRO 1: EXPORTACIONES DE CUEROS VACUNOS DE} BUENOS AIRES Y MONTEVIDEO, 1815-1882

\begin{tabular}{|c|c|c|c|c|c|}
\hline AÑO & BUENOS AIRES & $\%$ & MONTEVIDEO & $\%$ & TOTAL \\
\hline 1815 & 850242 & 75,95 & 269200 & 24,05 & 1119442 \\
\hline 1816 & 691321 & 69,99 & 296444 & 30,01 & 987765 \\
\hline 1817 & 798599 & 95,33 & 39115 & 4,67 & 837714 \\
\hline 1818 & 728539 & 92,30 & 60803 & 7,70 & 789342 \\
\hline 1819 & 519991 & 96,36 & 19650 & 3,64 & 539641 \\
\hline 1820 & 469138 & & & & \\
\hline 1822 & 590372 & & & & \\
\hline 1825 & 655255 & & & & \\
\hline 1829 & 854799 & 73,22 & 312613 & 26,78 & 1167412 \\
\hline 1830 & 965556 & 76,61 & 294754 & 23,39 & 1260310 \\
\hline 1835 & 534213 & 55,95 & 420513 & 44,05 & 954726 \\
\hline 1836 & 622702 & 54,81 & 513401 & 45,19 & 1136103 \\
\hline 1837 & 823635 & 57,16 & 617382 & 42,84 & 1441017 \\
\hline 1838 & 355993 & & & & \\
\hline 1839 & 8501 & & & & \\
\hline 1840 & 83779 & 6,24 & 1258345 & 93,76 & 1342124 \\
\hline 1841 & 2340638 & 66,26 & 1191897 & 33,74 & 3532535 \\
\hline 1842 & 1399471 & 55,09 & 1141054 & 44,91 & 2540525 \\
\hline 1843 & 2054715 & & & & \\
\hline 1844 & 1786351 & & & & \\
\hline \multicolumn{6}{|c|}{45 La Gaceta Mercantil, febrero de 1831.} \\
\hline \multicolumn{6}{|c|}{46 ARREDONDO, [44]. } \\
\hline \multicolumn{6}{|c|}{47 Comercio del Plata, Revista $C$} \\
\hline \multicolumn{6}{|c|}{48 Eduardo ACEVEDO, [7], t. II. } \\
\hline $49 \mathrm{~B}$ & RAN y NAHUM, [5], & I a V. & & & \\
\hline
\end{tabular}


CUADRO 1: EXPORTACIONES DE CUEROS VACUNOS DE BUENOS AIRES Y MONTEVIDEO, 1815-1882 (Continuación)

\begin{tabular}{|c|c|c|c|c|c|}
\hline AÑO & BUENOS AIRES & $\%$ & MONTEVIDEO & $\%$ & TOTAL \\
\hline 1845 & 1942297 & & & & \\
\hline 1846 & 436739 & 26,92 & 1185440 & 73,08 & 1622179 \\
\hline 1847 & 1545307 & 40,93 & 2229806 & 59,07 & 3775113 \\
\hline 1848 & 1384790 & 61,69 & 860060 & 38,31 & 2244850 \\
\hline 1849 & 2961342 & 97,76 & 67856 & 2,24 & 3029198 \\
\hline 1850 & 2424251 & 99,28 & 17695 & 0,72 & 2441946 \\
\hline 1851 & 2601140 & 97,57 & 64822 & 2,43 & 2665962 \\
\hline 1852 & 1976173 & 81,16 & 458863 & 18,84 & 2435036 \\
\hline 1853 & 1199935 & 61,07 & 765000 & 38,93 & 1964935 \\
\hline 1854 & 759968 & 57,10 & 571000 & 42,90 & 1330968 \\
\hline 1855 & 1300081 & 72,87 & 484000 & 27,13 & 1784081 \\
\hline 1856 & 1214772 & 71,72 & 479000 & 28,28 & 1693772 \\
\hline 1857 & 1409301 & 69,11 & 630000 & 30,89 & 2039301 \\
\hline 1858 & 1372625 & 70,80 & 566000 & 29,20 & 1938625 \\
\hline 1859 & 1508902 & & & & \\
\hline 1860 & 1613130 & & & & \\
\hline 1861 & 1438350 & & & & \\
\hline 1862 & 1551291 & 57,66 & 1139000 & 42,34 & 2690291 \\
\hline 1863 & & & 1406000 & & 1406000 \\
\hline 1865 & 2034000 & & & & 2034000 \\
\hline 1866 & 1980000 & & & & 1980000 \\
\hline 1867 & 2399000 & 67,50 & 1155000 & 32,50 & 3554000 \\
\hline 1868 & 2355000 & 73,00 & 871000 & 27,00 & 3226000 \\
\hline 1869 & 2928000 & 72,05 & 1136000 & 27,95 & 4064000 \\
\hline 1870 & 2712000 & 71,39 & 1087000 & 28,61 & 3799000 \\
\hline 1871 & 2433000 & 65,58 & 1277000 & 34,42 & 3710000 \\
\hline 1872 & 3240000 & 72,53 & 1227000 & 27,47 & 4467000 \\
\hline 1873 & 2671000 & 69,61 & 1166000 & 30,39 & 3837000 \\
\hline 1874 & 3106000 & 72,95 & 1152000 & 27,05 & 4258000 \\
\hline 1875 & 2883000 & 75,53 & 934000 & 24,47 & 3817000 \\
\hline 1876 & 2325000 & & & & 2325000 \\
\hline 1877 & 2488000 & 69,07 & 1114000 & 30,93 & 3602000 \\
\hline 1878 & 2239000 & 64,94 & 1209000 & 35,06 & 3448000 \\
\hline 1879 & 2337000 & 62,70 & 1390000 & 37,30 & 3727000 \\
\hline 1880 & 2791000 & 61,10 & 1777000 & 38,90 & 4568000 \\
\hline 1881 & 2192000 & 50,58 & 2142000 & 49,42 & 4334000 \\
\hline 1882 & 1945000 & 53,74 & 1674000 & 46,26 & 3619000 \\
\hline
\end{tabular}

R. I., 1999, $\mathrm{n}^{\circ} 215$ 
CUADRO 2: EXPORTACIONES DE CUEROS BAGUALES DE BUENOS AIRES Y MONTEVIDEO, 1815-1882

\begin{tabular}{|c|c|c|c|c|c|}
\hline AÑO & BUENOS AIRES & $\%$ & MONTEVIDEO & $\%$ & TOTAL \\
\hline 1815 & 214395 & & & & \\
\hline 1816 & 191705 & 95,74 & 8522 & 4,26 & 200227 \\
\hline 1817 & 223916 & & & & \\
\hline 1818 & 215862 & & & & \\
\hline 1819 & 142733 & & & & \\
\hline 1820 & 198992 & & & & \\
\hline 1822 & 421566 & & & & \\
\hline 1825 & 339703 & & & & \\
\hline 1829 & 64563 & 33,51 & 128105 & 66,49 & 192668 \\
\hline 1830 & 48851 & 18,00 & 222521 & 82,00 & 271372 \\
\hline 1831 & & & 182676 & & \\
\hline 1835 & 20813 & 28,58 & 52000 & 71,42 & 72813 \\
\hline 1836 & 40100 & 52,01 & 37000 & 47,99 & 77100 \\
\hline 1837 & 25367 & 51,38 & 24000 & 48,62 & 49367 \\
\hline 1838 & 20443 & & & & \\
\hline 1839 & 1320 & & & & \\
\hline 1840 & 4807 & 9,62 & 45177 & 90,38 & 49984 \\
\hline 1841 & 113192 & 68,19 & 52800 & 31,81 & 165992 \\
\hline 1842 & 58508 & 47,06 & 65824 & 52,94 & 124332 \\
\hline 1843 & 71804 & & & & \\
\hline 1844 & 41646 & & & & \\
\hline 1845 & 69412 & & & & \\
\hline 1846 & 54863 & 55,50 & 43995 & 44,50 & 98858 \\
\hline 1847 & 108183 & 42,24 & 147942 & 57,76 & 256125 \\
\hline 1848 & 93810 & 73,62 & 33620 & 26,38 & 127430 \\
\hline 1849 & 238514 & 98,82 & 2855 & 1,18 & 241369 \\
\hline 1850 & 187107 & 99,83 & 318 & 0,17 & 187425 \\
\hline 1851 & 140677 & & & & \\
\hline 1852 & 47371 & & & & \\
\hline 1853 & 151370 & 32,74 & 311000 & 67,26 & 462370 \\
\hline 1854 & 110828 & 32,81 & 227000 & 67,19 & 337828 \\
\hline 1855 & 167769 & 46,89 & 190000 & 53,11 & 357769 \\
\hline 1856 & 172055 & 53,76 & 148000 & 46,24 & 320055 \\
\hline 1857 & 278550 & 59,58 & 189000 & 40,42 & 467550 \\
\hline 1858 & 172606 & 60,01 & 115000 & 39,99 & 287606 \\
\hline 1859 & 188769 & & & & \\
\hline 1860 & 310040 & & & & \\
\hline 1861 & 209549 & & & & \\
\hline 1862 & 177128 & 57,86 & 129000 & 42,14 & 306128 \\
\hline
\end{tabular}


CUADRO 2: EXPORTACIONES DE BAGUAJES DE BUENOS AIRES Y MONTEVIDEO, 1815-1882 (Continuación)

\begin{tabular}{|c|c|c|c|c|c|}
\hline AÑO & BUENOS AIRES & $\%$ & MONTEVIDEO & $\%$ & TOTAL \\
\hline 1865 & 185600 & & & & \\
\hline 1866 & 126500 & & & & \\
\hline 1867 & 115600 & & & & \\
\hline 1868 & 113000 & & & & \\
\hline 1869 & 150400 & & & & \\
\hline 1870 & 102100 & & & & \\
\hline 1871 & 120400 & & & & \\
\hline 1872 & 208500 & & & & \\
\hline 1873 & 149400 & & & & \\
\hline 1874 & 255300 & & & & \\
\hline 1875 & 242500 & & & & \\
\hline 1876 & 195900 & & & & \\
\hline 1877 & 262200 & & & & \\
\hline 1878 & 202000 & & & & \\
\hline 1879 & 217400 & & & & \\
\hline 1880 & 326900 & & & & \\
\hline 1881 & 280600 & & & & \\
\hline 1882 & 213900 & & & & \\
\hline
\end{tabular}

CUADRO 3: EXPORTACIONES DE CUEROS VACUNOS DE BUENOS AIRES Y MONTEVIDEO, 1815-1882

\begin{tabular}{rccccc}
\hline AÑO & BUENOS AIRES & $\%$ & MONTEVIDEO & $\%$ & TOTAL \\
\hline 1815 & 6212 & & & & \\
1816 & 12924 & & & & \\
1817 & 12928 & & & & \\
1818 & 35979 & & & & \\
1819 & 34480 & & & & \\
1820 & 8949 & & & & \\
& & & & & \\
1822 & 33147 & & & & \\
& & & & & \\
1829 & 30334 & & & & \\
1830 & 6921 & & & & \\
& & & & & \\
1832 & & & & & \\
& & & & & \\
1835 & 130308 & 81,80 & 340000 & 20,41 & \\
1836 & 132580 & 79,59 & 39000 & 19,15 & 203706 \\
1837 & 164706 & 80,85 & & &
\end{tabular}

R. I., 1999, n. ${ }^{\circ} 215$ 
CUADRO 3: EXPORTACIONES DE IANA DE BUENOS AIRES Y MONTEVIDEO, 1815-1882 (Continuación)

\begin{tabular}{|c|c|c|c|c|c|}
\hline AÑO & BUENOS AIRES & $\%$ & MONTEVIDEO & $\%$ & TOTAL \\
\hline 1838 & 166796 & & & & \\
\hline 1839 & 25038 & & & & \\
\hline 1840 & 3818 & 4,22 & 86724 & 95,78 & 90542 \\
\hline 1841 & 304872 & 79,27 & 79740 & 20,73 & 384612 \\
\hline 1842 & 124696 & 57,53 & 92068 & 42,47 & 216764 \\
\hline 1843 & 172635 & & & & \\
\hline 1844 & 139215 & & & & \\
\hline 1845 & 172509 & & & & \\
\hline 1846 & 65197 & 37,08 & 110635 & 62,92 & 175832 \\
\hline 1847 & 317102 & 50,00 & 317126 & 50,00 & 634228 \\
\hline 1848 & 507300 & 76,72 & 153947 & 23,28 & 661247 \\
\hline 1849 & 934780 & 99,82 & 1649 & 0,18 & 936429 \\
\hline 1850 & 739550 & 99,80 & 1494 & 0,20 & 741044 \\
\hline 1851 & 769090 & & & & \\
\hline 1852 & 724268 & & & & \\
\hline 1853 & 808999 & 84,32 & 150457 & 15,68 & 959456 \\
\hline 1854 & 485380 & 92,81 & 37614 & 7,19 & 522994 \\
\hline 1855 & 1005358 & 96,41 & 37440 & 3,59 & 1042798 \\
\hline 1856 & 1126095 & 95,20 & 56770 & 4,80 & 1182865 \\
\hline 1857 & 1313353 & 94,31 & 79234 & 5,69 & 1392587 \\
\hline 1858 & 1259269 & 93,22 & 91598 & 6,78 & 1350867 \\
\hline 1859 & 1591823 & & & & \\
\hline 1860 & 1410535 & & & & \\
\hline 1861 & 2041845 & & & & \\
\hline 1862 & 2346970 & 85,21 & 407488 & 14,79 & 2754458 \\
\hline 1863 & & & 521739 & & \\
\hline 1865 & 4776174 & & & & \\
\hline 1866 & 4699478 & & & & \\
\hline 1867 & 5514870 & 78,87 & 1477478 & 21,13 & 6992348 \\
\hline 1868 & 6106957 & 78,76 & 1646609 & 21,24 & 7753565 \\
\hline 1869 & 6300087 & 79,11 & 1663652 & 20,89 & 7963739 \\
\hline 1870 & 5713391 & 83,97 & 1090870 & 16,03 & 6804261 \\
\hline 1871 & 6223043 & 82,10 & 1356870 & 17,90 & 7579913 \\
\hline 1872 & 8037043 & 85,04 & 1413565 & 14,96 & 9450609 \\
\hline 1873 & 7281130 & 83,94 & 1393478 & 16,06 & 8674609 \\
\hline 1874 & 6974522 & 82,56 & 1473652 & 17,44 & 8448174 \\
\hline 1875 & 7889043 & 90,86 & 793652 & 9,14 & 8682696 \\
\hline 1876 & 7786609 & & & & \\
\hline 1877 & 8464696 & 85,02 & 1490870 & 14,98 & 9955565 \\
\hline 1878 & 7121217 & 82,88 & 1470609 & 17,12 & 8591826 \\
\hline 1879 & 8009739 & 83,72 & 1557217 & 16,28 & 9566957 \\
\hline 1880 & 8479826 & 83,86 & 1631739 & 16,14 & 10111565 \\
\hline 1881 & 9109304 & 85,21 & 1581043 & 14,79 & 10690348 \\
\hline 1882 & 9660435 & 83,95 & 1846522 & 16,05 & 11506957 \\
\hline
\end{tabular}


CUADRO 4: EXPORTACIONES DE TASAJO DE BUENOS AIRES Y MONTEVIDEO, 1822-1882

\begin{tabular}{|c|c|c|c|c|c|}
\hline AÑO & BUENOS AIRES & $\%$ & MONTEVIDEO & $\%$ & TOTAL \\
\hline 1822 & 87663 & & & & \\
\hline 1825 & 130361 & & & & \\
\hline 1829 & 164818 & 82,18 & 35732 & 17,82 & 200550 \\
\hline 1830 & 261284 & 72,03 & 101479 & 27,97 & 362763 \\
\hline 1834 & & & 180950 & & \\
\hline 1835 & 119017 & 39,68 & 180950 & 60,32 & 299967 \\
\hline 1836 & 150579 & 32,95 & 306354 & 67,05 & 456933 \\
\hline 1837 & 178877 & 34,60 & 338126 & 65,40 & 517003 \\
\hline 1838 & 165304 & & & & \\
\hline 1839 & 6670 & & & & \\
\hline 1840 & 8630 & 1,27 & 673362 & 98,73 & 681992 \\
\hline 1841 & 217671 & 26,52 & 603052 & 73,48 & 820723 \\
\hline 1842 & 133795 & 26,68 & 367715 & 73,32 & 501510 \\
\hline 1843 & 182940 & & & & \\
\hline 1844 & 328182 & & & & \\
\hline 1845 & 274330 & & & & \\
\hline 1846 & 21298 & & & & 21298 \\
\hline 1847 & 225481 & 56,06 & 176717 & 43,94 & 402198 \\
\hline 1848 & 314352 & 94,88 & 16963 & 5,12 & 331315 \\
\hline 1849 & 559969 & 99,60 & 2273 & 0,40 & 562242 \\
\hline 1850 & 390731 & & & & 390731 \\
\hline 1851 & 431873 & & & & \\
\hline 1852 & 521975 & & & & \\
\hline 1853 & 335165 & & & & \\
\hline 1854 & 157998 & & & & \\
\hline 1855 & & & 200000 & & \\
\hline 1856 & & & 231000 & & \\
\hline 1857 & & & 301000 & & \\
\hline 1858 & & & 283000 & & \\
\hline 1859 & & & 305000 & & \\
\hline 1860 & & & 413000 & & \\
\hline 1861 & & & 392000 & & \\
\hline 1862 & & & 741000 & & \\
\hline 1863 & & & 911957 & & \\
\hline 1865 & 772587 & & & & \\
\hline 1866 & 497674 & & & & \\
\hline 1867 & 695217 & 45,08 & 847000 & 54,92 & 1542217 \\
\hline 1868 & 603783 & 42,95 & 802000 & 57,05 & 1405783 \\
\hline 1869 & 824022 & 53,90 & 704891 & 46,10 & 1528913 \\
\hline 1870 & 841957 & 60,11 & 558652 & 39,89 & 1400609 \\
\hline
\end{tabular}


CUADRO 4: EXPORTACIONES DE TASAJO DE BUENOS AIRES Y MONTEVIDEO, 1822-1882 (Continuación)

\begin{tabular}{cccccc}
\hline AÑO & BUENOS AIRES & $\%$ & MONTEVIDEO & $\%$ & TOTAL \\
\hline 1871 & 700826 & 55,46 & 562804 & 44,54 & 1263630 \\
1872 & 905630 & 54,95 & 742543 & 45,05 & 1648174 \\
1873 & 669848 & 45,72 & 795174 & 54,28 & 1465022 \\
1874 & 552935 & 41,48 & 780239 & 58,52 & 1333174 \\
1875 & 740174 & 60,16 & 490261 & 39,84 & 1230435 \\
1876 & 642239 & & & & \\
1877 & 841717 & 63,02 & 494022 & 36,98 & 1335739 \\
1878 & 729978 & 50,46 & 716630 & 49,54 & 1446609 \\
1879 & 702391 & 57,95 & 509761 & 42,05 & 1212152 \\
1880 & 567587 & 44,12 & 718978 & 55,88 & 1286565 \\
1881 & 486935 & 44,57 & 605478 & 55,43 & 1092413 \\
1882 & 586891 & 44,24 & 739696 & 55,76 & 1326587 \\
\hline
\end{tabular}

CUADRO 5: PONDERACIÓN DE LOS PRODUCTOS EXPORTADOS POR BUENOS AIRES Y MONTEVIDEO SOBRE EL VALOR TOTAL (EN PORCENTAJES)

\begin{tabular}{|c|c|c|}
\hline & \multicolumn{2}{|c|}{ BUENOS AIRES } \\
\hline PRODUCTOS & 1849 & 1877 \\
\hline CUEROS VACUNOS & 58,3 & 26,8 \\
\hline LANA & 10,5 & 41,8 \\
\hline TASAJO & 8,8 & 6,2 \\
\hline SEBO & 14,5 & 9,5 \\
\hline Otros & 7,9 & 15,7 \\
\hline \multirow[t]{2}{*}{ total } & 100,0 & 100,0 \\
\hline & \multicolumn{2}{|c|}{ MONTEVIDEO } \\
\hline PRODUCTOS & $1846-50$ & $1877-80$ \\
\hline CUEROS VACUNOS & 81,0 & 29,4 \\
\hline LANA & 6,0 & 19,3 \\
\hline TASAJO & 5,0 & 15,9 \\
\hline SEBO & 5,0 & 7,5 \\
\hline Otros & 3,0 & 27,9 \\
\hline total & 100,0 & 100,0 \\
\hline
\end{tabular}

R. I., 1999, n..$^{\circ} 215$ 
The aim of this article is to analyze the export growth rate in the Rio de la Plata as well as the trading competence between the seaports of Buenos Aires and Montevideo in their endeavours to homogenize the commercial fluxes. By means of quantitative and qualitative analyses of the traffic and the trading policies implemented between 1830 and 1850, new evidence is offered which reasertains the advantages and disadvantages of business in the Rio de la Plata ambits as from mid $19^{\text {th }}$ Century.

R. I., $1999, \mathrm{n}^{\circ} 215$ 